Supporting Information

\title{
Highly Water-Tolerant TEMPO-Oxidized Cellulose Nanofiber Films Using Maleic Anhydride/Wax Copolymer
}

\author{
Toshiki Tamiya ${ }^{\#}$, Raghav Soni", Yu-I Hsu*, and Hiroshi Uyama*
}

Department of Applied Chemistry, Graduate School of Engineering, Osaka University, 2-1 Yamadaoka, Suita, Osaka, 565-0871 Japan

${ }^{\#}$ Both author has equal contribution

* Corresponding Author

E-mail: uyama@chem.eng.osaka-u.ac.jp

TEL: +81-6-6879-7364

FAX: +81-6-6879-7367 
(a)

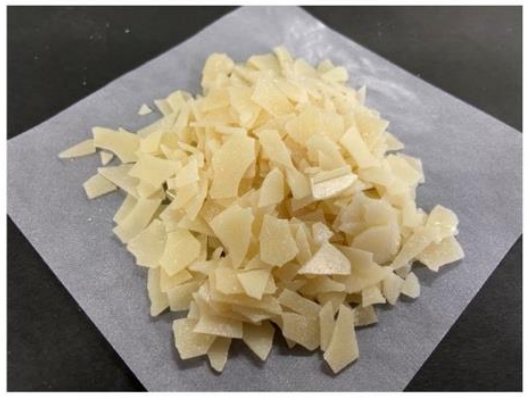

\begin{tabular}{cc} 
Physical properties & Value \\
\hline $\begin{array}{c}\text { Viscosity } \\
\left(\mathrm{mPa} \cdot \mathrm{s}, \text { at } 120^{\circ} \mathrm{C}\right)\end{array}$ & 87
\end{tabular}

Saponification value $(\mathrm{mgKOH} / \mathrm{g})$

(b)

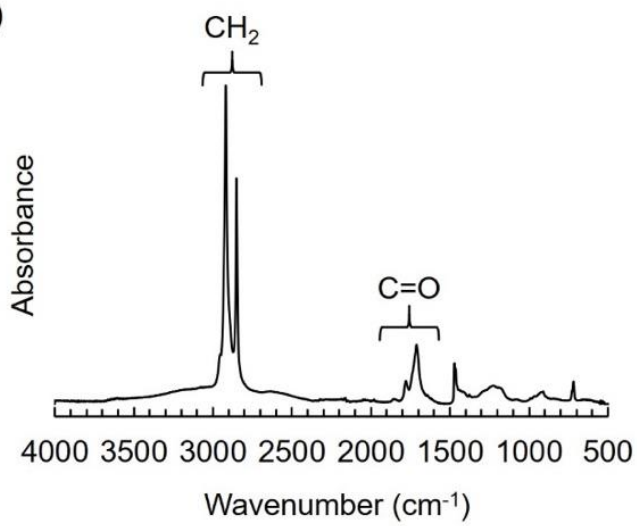

(c)

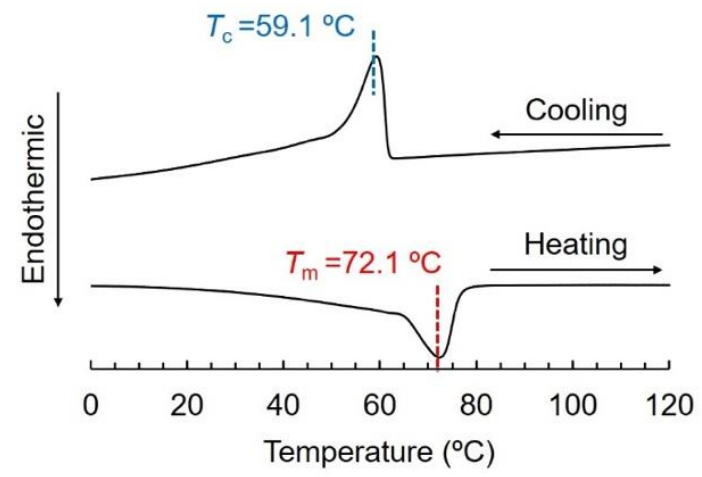

Figure S1. Characterization of MAW: (a) Photo image and physical properties [the data were supplied by Nippon Seiro], (b) FT-IR spectra, (c) DSC $1^{\text {st }}$ cooling and $2^{\text {nd }}$ heating charts. 


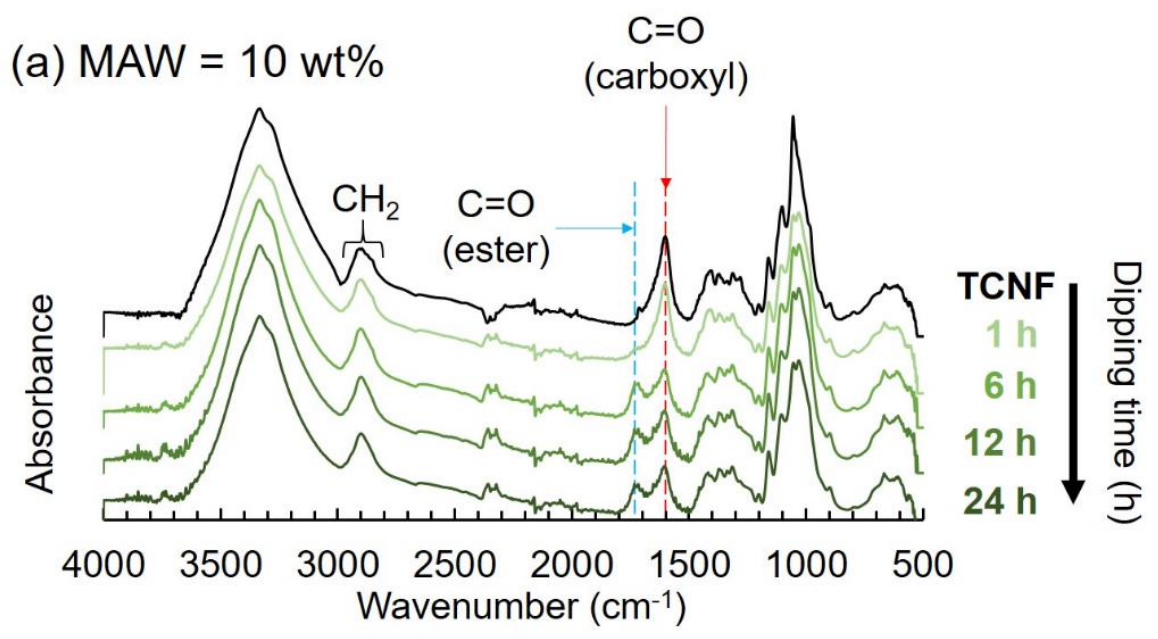

(b) $\mathrm{MAW}=20 \mathrm{wt} \%$

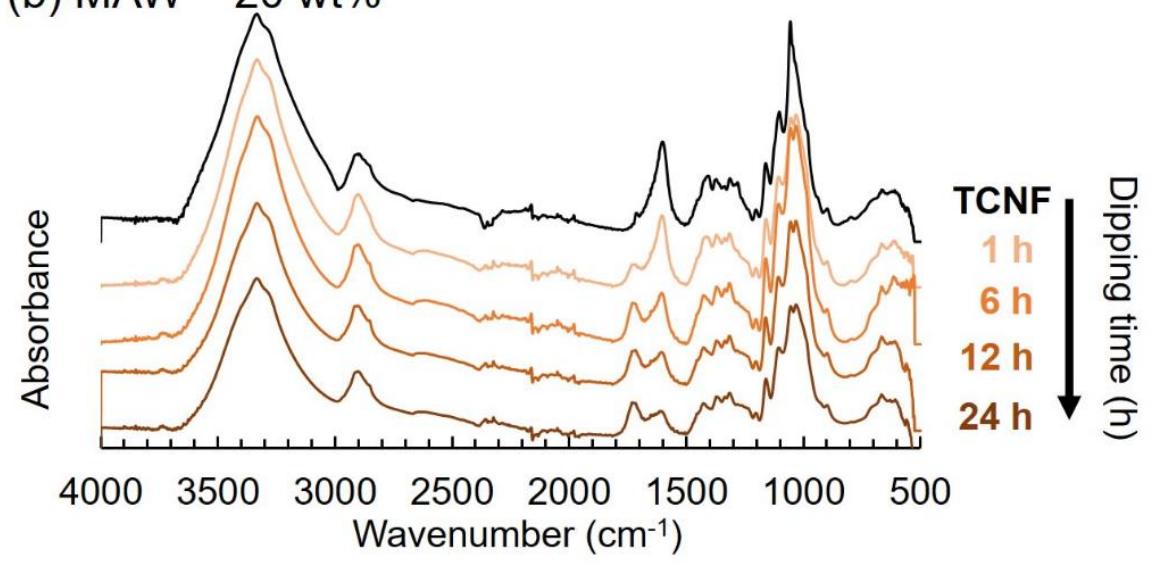

(c) $M A W=40 w t \%$

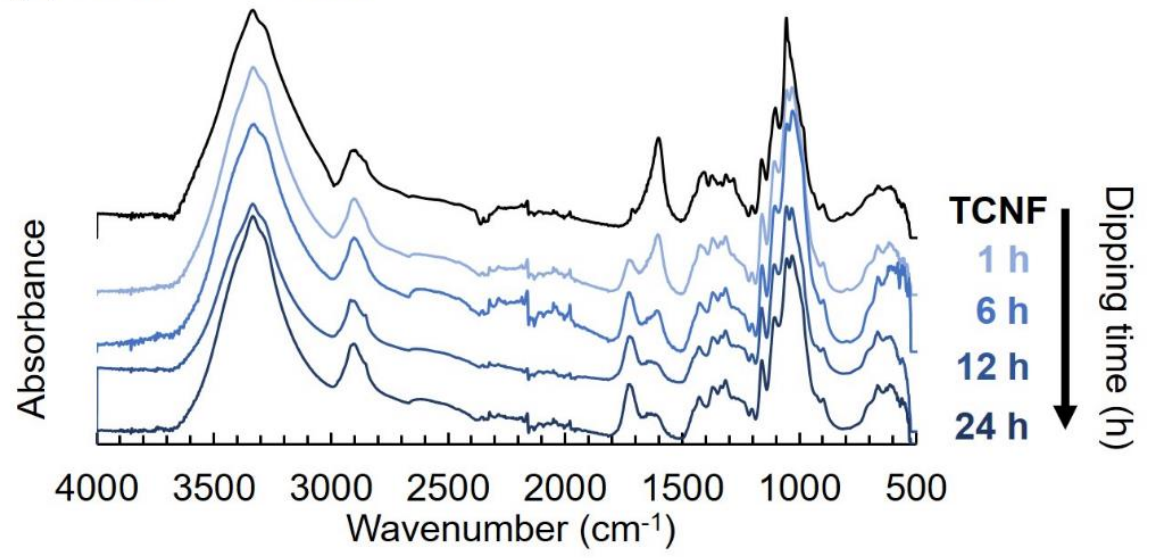

Figure S2. FT-IR spectra of M-TCNF with change in the reaction time at MAW = (a) $10 \mathrm{wt} \%$, (b) $20 \mathrm{wt} \%$, and (c) $40 \mathrm{wt} \%$, respectively. 


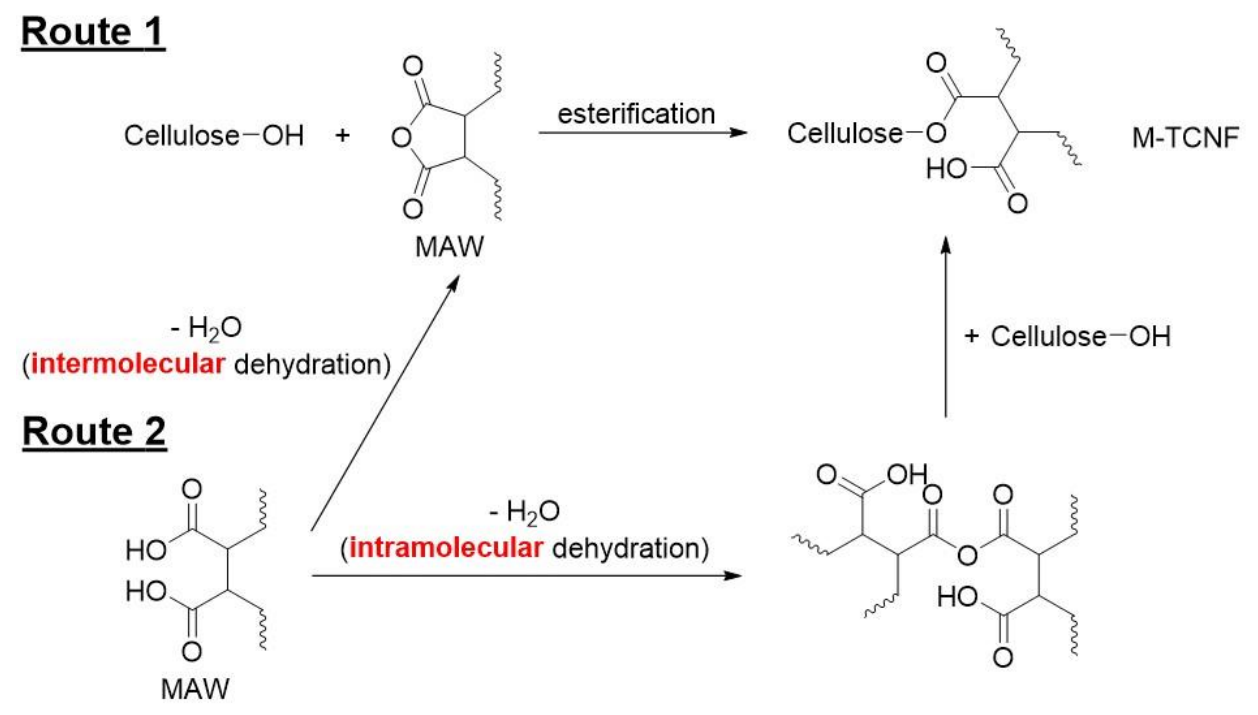

Figure S3. Expected reaction scheme of MAW with cellulose in limonene. 

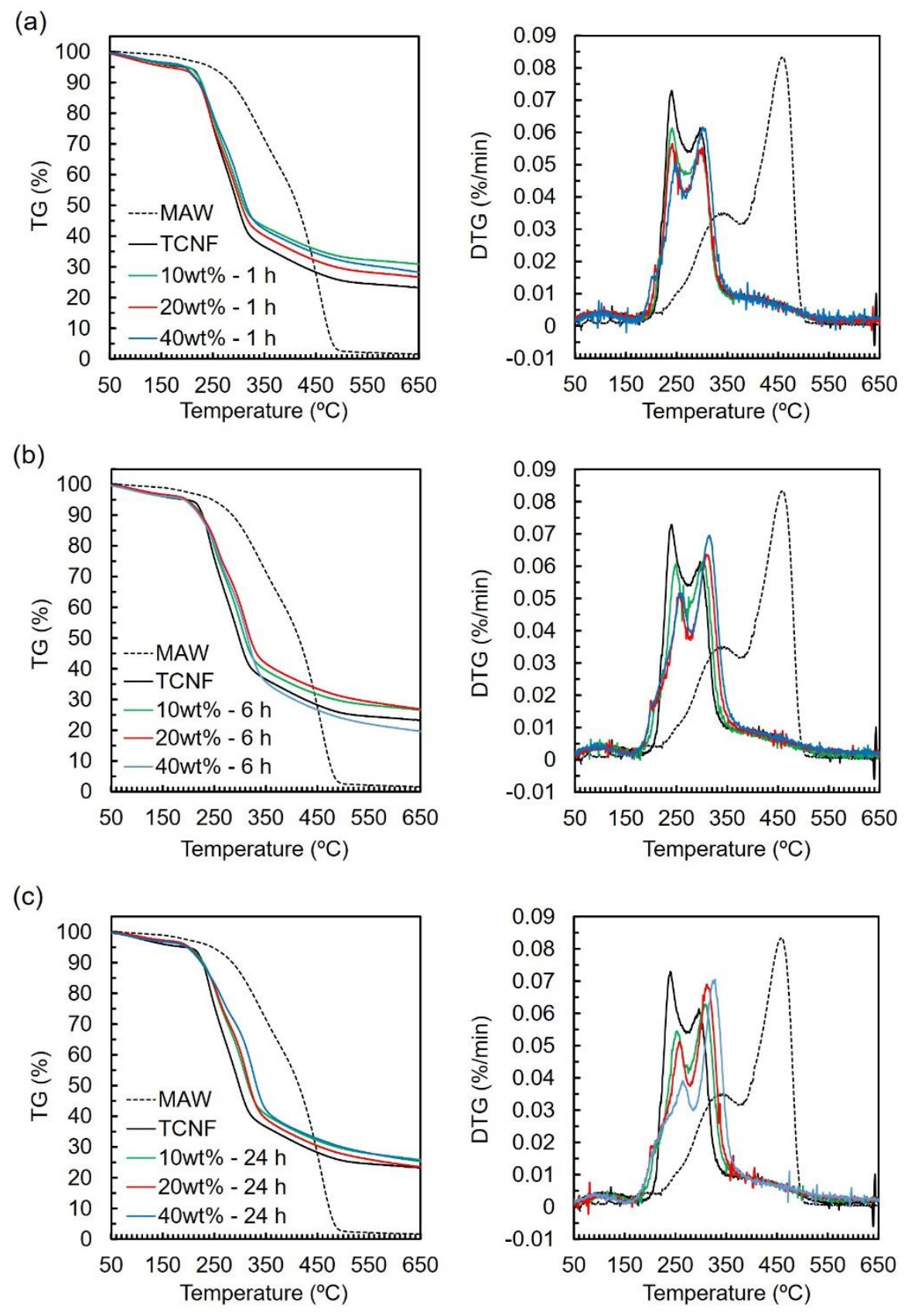

Figure S4. TGA curves (left column) and DTG charts (right column) of M-TCNF with change in the MAW concentration at reaction time $=$ (a) $1 \mathrm{~h}$, (b) $6 \mathrm{~h}$, and (c) $24 \mathrm{~h}$, respectively. 
(a)

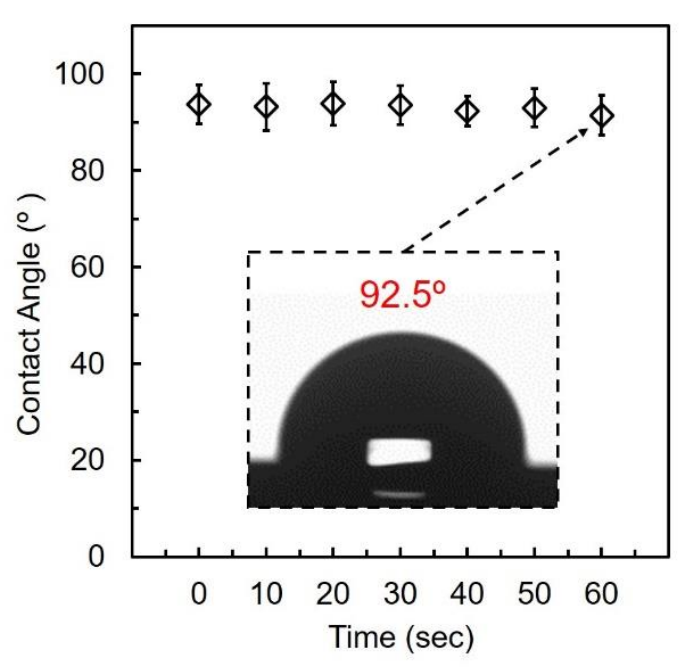

(c) MAW $=20 w t \%$

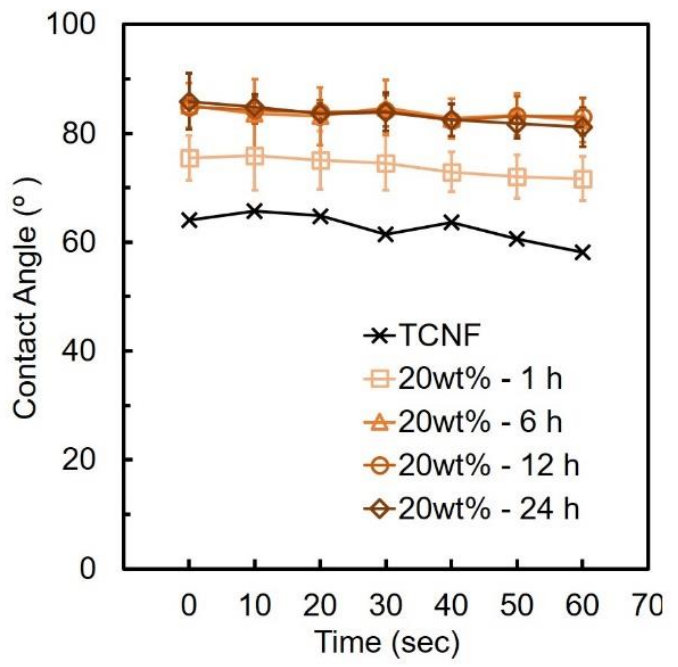

(b) $M A W=10 w t \%$

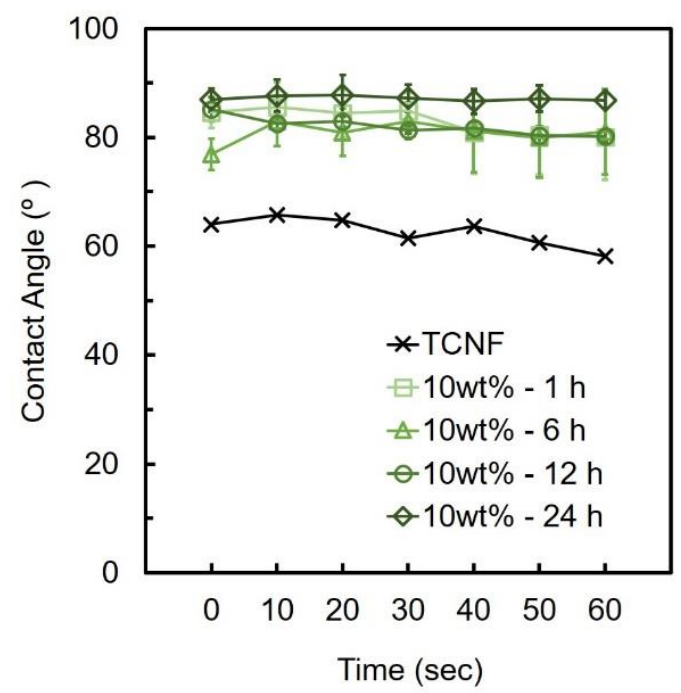

(d) MAW $=40 \mathrm{wt} \%$

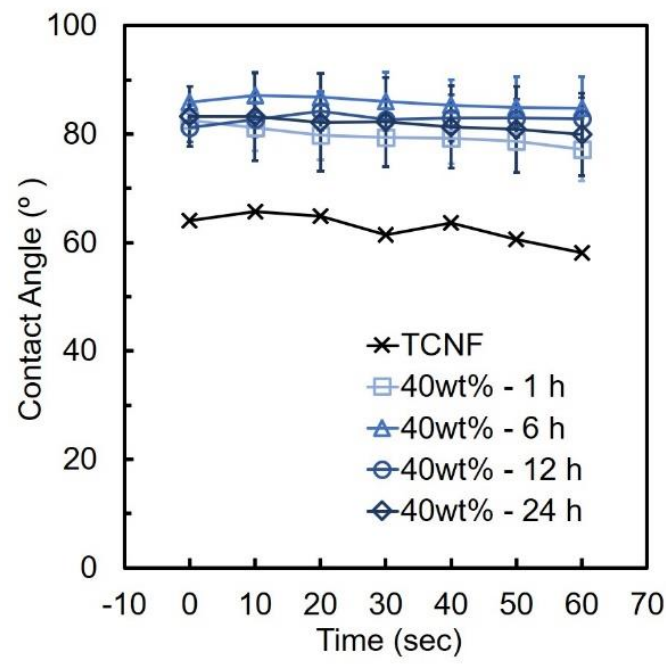

Figure S5. WCA value of (a) MAW sheet and (b-d) M-TCNF films [(b) MAW = $10 \mathrm{wt} \%$, (c) $\mathrm{MAW}=20 \mathrm{wt} \%$, (d) MAW = $40 \mathrm{wt} \%$ ] as a function of time (sec.). 


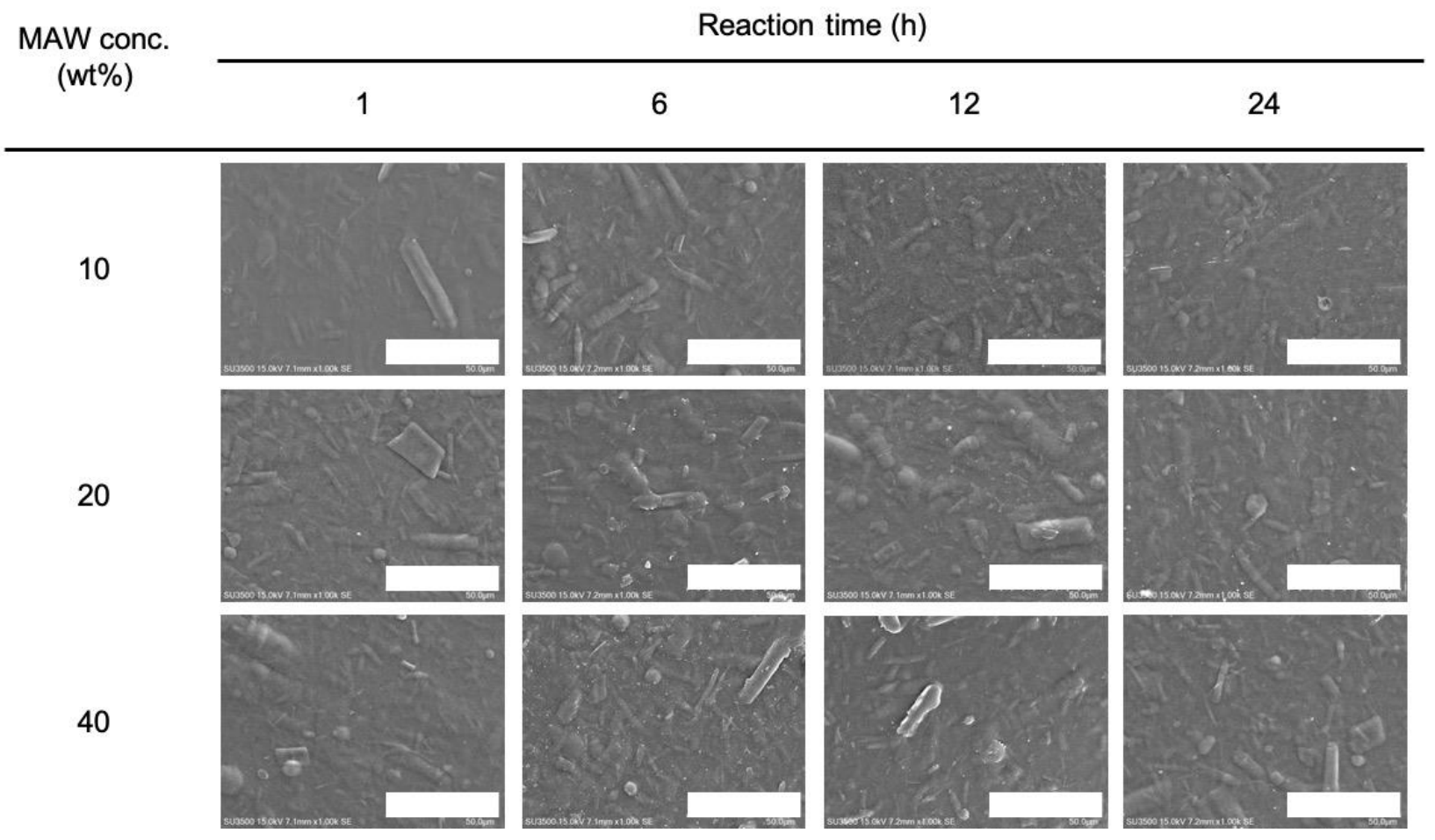

Figure S6. SEM images of M-TCNF film surface prepared under the various conditions (MAW conc. $=10,20,40 \mathrm{wt} \%$ and reaction time $=1,6,12,24 \mathrm{~h}$ ) [Scale bar: $50 \mu \mathrm{m}]$.

(a)

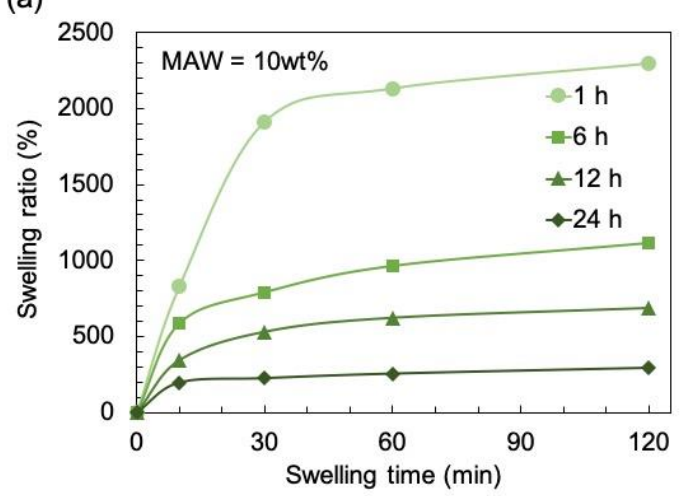

(b)

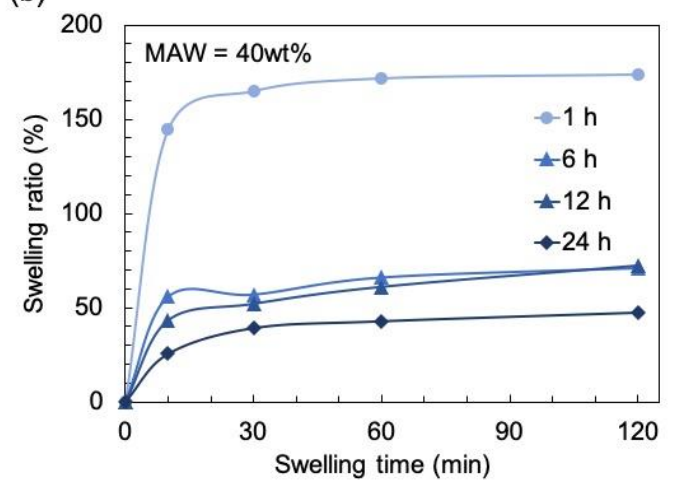

Figure S7. Water swelling behavior of M-TCNF at MAW = (a) $10 \mathrm{wt} \%$ and (b) $20 \mathrm{wt} \%$ as a function of swelling time (min). 